\title{
Editorial: Malnutrition: A Cause or a Consequence of Poverty?
}

\author{
Zheng Feei Ma ${ }^{1 *}$, Chee Woon Wang ${ }^{2}$ and Yeong Yeh Lee ${ }^{3 *}$ \\ ${ }^{1}$ Department of Health and Environmental Sciences, Xi'an Jiaotong-Liverpool University, Suzhou, China, ${ }^{2}$ Department of \\ Biochemistry, Faculty of Medicine, MAHSA University, Jenjarom, Malaysia, ${ }^{3}$ School of Medical Sciences, Universiti Sains \\ Malaysia, Kota Bharu, Malaysia
}

Keywords: malnutrition, public health, global health, poverty, inequality

\section{Editorial on the Research Topic}

\section{Malnutrition: A Cause or a Consequence of Poverty?}

Malnutrition is one of the universal public health issues affecting populations worldwide. In addition, it is an obstacle to the eradication of the poverty. Therefore, it is estimated that with the elimination of malnutrition, about $32 \%$ of the worldwide disease burden could be removed (1). The 2030 Agenda for Sustainable Development and its 17 Sustainable Development Goals (SDGs) has provided a framework to promote sustainable development (2). One of the SDGs, SDG 2, is to "end hunger, achieve food security and improved nutrition, and promote sustainable

OPEN ACCESS

Edited and reviewed by: Aldo Rosano,

National Institute for the Analysis of Public Policy, Italy

${ }^{*}$ Correspondence: Yeong Yeh Lee justnleeyy@gmail.com Zheng Feei Ma zhengfeeima@gmail.com

Specialty section:

This article was submitted to Life-Course Epidemiology and Social Inequalities in Health,

a section of the journal

Frontiers in Public Health

Received: 16 October 2021

Accepted: 07 December 2021

Published: 04 January 2022

Citation:

Ma ZF, Wang CW and Lee YY (2022)

Editorial: Malnutrition: A Cause or a Consequence of Poverty?

Front. Public Health 9:796435.

doi: 10.3389/fpubh.2021.796435 agriculture" (2). Malnutrition can be categorized into undernutrition (e.g., wasting, stunting, and underweight), overnutrition (e.g., obesity), and micronutrient-related malnutrition (3). Globally, it is estimated that 149 million children are stunted and 50 million are wasted (4). Undernutrition has been reported to be accounted for $45 \%$ of all child deaths either as a direct or underlying cause (5). Also, an estimated of 40 million children under 5 years are considered overweight and 678 million adults are categorized to be obese (4). The first 1,000 days of life has been targeted as the window period to address malnutrition because malnutrition manifestation and symptoms usually begin to appear during this period (6). Therefore, the collection of the published papers in this Research Topic aimed to focus on nutrition education, social determinants of health, factors, and consequences of malnutrition, and suggestions to prevent malnutrition in populations (Alves et al.; Jansen et al.; le Roux et al.; Siddiqui et al.).

Malnutrition and poverty have become two sides of a same coin that are ravaging the developing countries, especially in the African continent (7). Although poverty has reported to be the main cause of malnutrition, malnutrition at an early age can deepen the influence of poverty and entrap these malnourished individuals in the "cycle of poverty" with potentially serious and long lasting health consequences (8). Studies have reported that both environmental and dietary factors are one of the causes of the malnutrition, especially in children. Diet and diseases are considered the primary determinants, with access to health care facilities, healthy food and physical environment, nutrition knowledge, feeding practices, education level, household income, and household food security influenced by the socio-demographics (9).

However, it is very challenging to determine if malnutrition can be considered a cause or consequence of poverty (Siddiqui et al.). Individuals living in poverty have limited access to necessities such as clean water, hygiene, and healthy food products. The consequences of poverty on individuals include food insecurity, poor health, and nutritional status (Siddiqui et al.). On the other hand, when nutritional status of individuals is improved, good health can be achieved. 
Consequently, this can contribute to increased work productivity levels of individuals, which can potentially lead to increased income of individuals (Siddiqui et al.). Poverty is associated with hidden hunger and nutrient deficiencies, which exacerbate the severity of malnutrition in individuals. Therefore, both malnutrition and poverty seem to reinforce each other as a vicious cycle (Siddiqui et al.).

The COVID-19 pandemic has exacerbated the severity of malnutrition issue, especially for the individuals susceptible to poverty (10). Some of the impacts of the COVID-19 pandemic on the food systems include the restrictions on movement of food products, food price volatility, and disruptions on food supply chain. In addition, due to the COVID-19 pandemic, the reduction in household income has affected the ability of the household to purchase food, which further compounded the food security issue among individuals living in poverty. The prevalence of wasting has been predicted to increase by $14 \%$ due to the COVID-19 pandemic (11). There have been increasingly studies that reported the importance of adequate nutrition in resilience to infection and as a mediator of its effects $(12,13)$. Sufficient dietary intake of macronutrients and micronutrients are essential for maintaining proper immune functioning (14). Undernutrition, especially in children can potentially lead to immune dysfunction and increased susceptibility to infectious diseases. Overnutrition can develop into overweight and obesity, which increases the risk of developing its comorbidities, such as cardiovascular disease (CVD) and diabetes. These comorbidities have been reported to be known risk factors for COVID-19 because they can increase the risk of SARS-CoV-2 infection and developing severe COVID-19 complications (15-17).

\section{CALL TO ACTION}

Several solutions have been proposed to address the burden of malnutrition and poverty. These include: healthy food and

\section{REFERENCES}

1. Katona P, Katona-Apte J. The interaction between nutrition and infection. Clin Infect Dis. (2008) 46:1582-8. doi: 10.1086/587658

2. UN General Assembly. Transforming our World: The 2030 Agenda for Sustainable Development. Report No. A/RES/70/1. (2015). Available online at: http://www.un.org/ga/search/view_doc.asp?symbol=A/RES/ 70/1andLang=E (accessed July 3, 2021).

3. WHO. Malnutrition: Key Facts 2020. (2020). Available online at: https://www. who.int/news-room/fact-sheets/detail/malnutrition (accessed July 25, 2021).

4. Development Initiatives. Global Nutrition Report: Action on Equity to End Malnutrition. UNICEF (2020)

5. Black RE, Victora CG, Walker SP, Bhutta ZA, Christian P, De Onis $\mathrm{M}$, et al. Maternal and child undernutrition and overweight in low-income and middle-income countries. Lancet. (2013) 382:427-51. doi: 10.1016/S0140-6736(13)60937-X

6. Wells JCK, Marphatia AA, Amable G, Siervo M, Friis H, Miranda JJ, et al. The future of human malnutrition: rebalancing agency for better nutritional health. Glob Health. (2021) 17:119. doi: 10.1186/s12992-021-00767-4

7. Adeyeye SAO, Adebayo-Oyetoro AO, Tiamiyu HK. Poverty and malnutrition in Africa: a conceptual analysis. Nutr Food Sci. (2017) 47:754-64. doi: 10.1108/NFS-02-2017-0027 physical environment, access to basic services (e.g., wash, sanitation, hygiene, and health care), diverse and nutritious food products, and exclusive breastfeeding for the first 6 months of life. In addition, all nutrition experts and policy makers must work together to strengthen the government agencies that focuses on nutrition policy and address urgent nutrition problems across the life cycle including infants, children, elderly, pregnant, and lactating women (18). Data on nutrition status of vulnerable populations should be routinely collected (18). Health economists should perform cost analyses on nutrition care, which translate nutrition policies into health care practice by the government (18). Synergistic collaboration between stakeholders in nutrition sectors should be encouraged to meet local and national nutrition goals set by the government (18). Nutrition education programmes should be developed and promoted to the general population to increase their awareness of healthier dietary choices (18).

Therefore, combating malnutrition, coupled with the COVID-19 pandemic, is one of the greatest global health challenges in the twenty-first century, which has disproportionally affected vulnerable groups. In addition, there is a need to build a sustainable and resilient food system that can provide adequate food supplies for all. Given the relationship between malnutrition and poverty, improved nutrition can help to lay the foundation for a stable population with progress made in education, health, and women empowerment because poverty and social inequality are reduced.

\section{AUTHOR CONTRIBUTIONS}

ZFM drafted and wrote the first draft of the manuscript. All authors reviewed and revised the manuscript, agreed to be accountable for all aspects of the work, read, and approved the final manuscript.
8. Ord J, Monks A. Food poverty and youth work - a community response. Crit Soc Policy. (2021) 42:64-84. doi: 10.1177/02610183219 96534

9. Azétsop J, Joy TR. Access to nutritious food, socioeconomic individualism and public health ethics in the USA: a common good approach. Philos Ethics Humanit Med. (2013) 8:16-16. doi: 10.1186/1747-5341-8-16

10. Osendarp S, Akuoku JK, Black RE, Headey D, Ruel M, Scott N, et al. The COVID-19 crisis will exacerbate maternal and child undernutrition and child mortality in low- and middle-income countries. Nature Food. (2021) 2:476-84. doi: 10.1038/s43016-021-0 0319-4

11. Headey D, Heidkamp R, Osendarp S, Ruel M, Scott N, Black R, et al. Impacts of COVID-19 on childhood malnutrition and nutrition-related mortality. Lancet. (2020) 396:519-21. doi: 10.1016/S0140-6736(20)31647-0

12. Belanger MJ, Hill MA, Angelidi AM, Dalamaga M, Sowers JR, Mantzoros CS. Covid-19 and disparities in nutrition and obesity. N Engl J Med. (2020) 383:e69. doi: 10.1056/NEJMp2021264

13. Mehta S. Nutritional status and COVID-19: an opportunity for lasting change? Clin Med. (2020) 20:270-3. doi: 10.7861/clinmed.2020-0187

14. Naja F, Hamadeh R. Nutrition amid the COVID-19 pandemic: a multi-level framework for action. Eur J Clin Nutr. (2020) 74:1117-21. doi: 10.1038/s41430-020-0634-3 
15. Cao Y, Ma ZF, Zhang Y, Zhang Y. Evaluation of lifestyle, attitude and stressful impact amid COVID-19 among adults in Shanghai, China. Int J Environ Health Res. (2020) 2020:1-10. doi: 10.1080/09603123.2020.18 41887

16. Tan M, He FJ, MacGregor GA. Obesity and COVID-19: the role of the food industry. BMJ. (2020) 369:m2237. doi: 10.1136/bmj.m2237

17. Zhang Y, Ma ZF. Impact of the COVID-19 pandemic on mental health and quality of life among local residents in Liaoning Province, China: a cross-sectional study. Int $J$ Environ Res Public Health. (2020) 17:2381. doi: 10.3390/ijerph170 72381

18. Herrera Cuenca M, Proaño GV, Blankenship J, Cano-Gutierrez C, Chew STH, Fracassi P, et al. Building global nutrition policies in health care: insights for tackling malnutrition from the Academy of Nutrition and Dietetics 2019 Global Nutrition Research and Policy Forum. J Acad Nutr Diet. (2020) 120:1407-16. doi: 10.1016/j.jand.2020. 03.011
Conflict of Interest: The authors declare that the research was conducted in the absence of any commercial or financial relationships that could be construed as a potential conflict of interest.

Publisher's Note: All claims expressed in this article are solely those of the authors and do not necessarily represent those of their affiliated organizations, or those of the publisher, the editors and the reviewers. Any product that may be evaluated in this article, or claim that may be made by its manufacturer, is not guaranteed or endorsed by the publisher.

Copyright (c) $2022 \mathrm{Ma}$, Wang and Lee. This is an open-access article distributed under the terms of the Creative Commons Attribution License (CC BY). The use, distribution or reproduction in other forums is permitted, provided the original author(s) and the copyright owner(s) are credited and that the original publication in this journal is cited, in accordance with accepted academic practice. No use, distribution or reproduction is permitted which does not comply with these terms. 